\title{
3D GEOVISUALIZATION - DEFINITION AND STRUCTURES FOR THE ASSESSMENT OF USEFULNESS
}

\author{
S. Bleisch \\ Institute of Geomatics Engineering, FHNW University of Applied Sciences Northwestern Switzerland, \\ Muttenz, Switzerland - susanne.bleisch@fhnw.ch
}

Commission II, WG II/6

KEY WORDS: Three-dimensional, Spatial, Visualization, Data, Exploration, Analysis, Tasks, Proposal

\begin{abstract}
:
3D geovisualizations are quite popular, typical examples include 3D city models or virtual globes. They are reported to be more useful when they not only depict the real world but also include additional information. The creation of 3D geovisualizations is often very technology driven and we are yet missing solid theory. The paper aims to compile definitions and structures that allow the consideration and evaluation of the usefulness of 3D geovisualization with additional abstract information less focussing on technical and implementational aspects. The different purposes of 3D geovisualizations, as illustrated through the geovisualization cube, together with considerations of the specific characteristics of 3D visualizations, for example the inherent need for navigation, build the base for conscious design decisions. Those decisions can build upon existing theories from related disciplines, such as cartography or information visualization, but need to consider onto what dimension of the three-dimensional space the data is mapped. A categorisation of the use of 3D space is discussed before reviewing different task definitions. A generic task structure which allows separation between interaction and navigational tasks together with the presented definitions and the categorisation of using 3D space build the basic framework for considering, evaluating and discussing the usefulness of 3D geovisualizations and ultimately support 3D geovisualization theory building. The knowledge of what works well and is useful in specific contexts can improve future technological developments and hopefully make 3D geovisualizations become an important tool for the visual exploration of 3D geospatial data sets.
\end{abstract}

\section{INTRODUCTION}

\subsection{Stage of 3D geovisualization developments and use}

$3 \mathrm{D}$ geovisualization is a quite generic term that is used for a range of 3D visualizations representing the real world, parts of the real world or other data with a spatial reference. Especially with the advent of virtual globes or geobrowsers like Google Earth (Google 2011) or already earlier since the vision about digital earth (Gore 1998) they are increasingly popular and many people know about 3D geovisualizations even though they may not call them so. Bartoschek \& Schönig (2008) did a study on the streets of Münster, Westfalen where they found out that $65 \%$ of the participants are familiar with virtual globes such as Google Earth. Many of the 3D geovisualizations focus on representing the landscape of the real world and often also real world objects such as buildings. Typical examples are digital elevation models draped with ortho or satellite imagery and more or less detailed 3D city models.

Craglia et al. (2012) review the developments since the original proposal of digital earth and propose an updated vision for 2020. Interestingly they mention the issue of visualization as being far developed. In regard to the visualization technology, e.g. hardware or rendering techniques, they may be right. However, there has been much less improvement on the theory. Questions such as what are appropriate 3D geovisualizations, how can different types of data be suitably represented in a single virtual environment or what are the merits of realistic or abstract representation styles are less often asked or even answered. Goodchild (1999) analyses Gore's (1999) vision of digital earth and lists the integration of various data and cartographic techniques and visualizations as important research challenges. Although there is research in regard to these topics (e.g. Döllner \& Walter 2003 or Mower 2011 on nonphotorealistic renderings) most research focusses on technology and processes and rarely evaluates the usefulness or the cognitive understanding of the results. Leonowicz et al. (2010) present work where cognitive requirements have driven technological developments. Nevertheless, Wood et al.'s (2005) statement that most 3D geovisualization approaches are technology driven rather than theory driven is still true. They note that there "is a risk that, for example, a virtual walkthrough or fly-by will meet society's zeitgeist more than cognitive cartographic requirements." (Wood et al. 2005, p. 306) Often we seem content if we achieve 3D geovisualization results that are, in representation and handling, no worse than Google Earth. As Wood et al. (2005) remark, we still know too little about when and how 3D visualizations can be used appropriately and effectively. More recently, Petzold \& Matthias (2011, p.40) ask for the "killer application" of 3D city models. They conclude that there are uses of 3D city models but rarely an application that would not succeed without 3D. Their review indicates that $3 \mathrm{D}$ city models are generally more useful when they include additional data, e.g. solar potential information, invisible drains or cables or the distribution of air pollution, which can be viewed or analysed in combination with the representation of the visible real world.

Technology and automation of processes are very important as today's amounts of information and update rates of information cannot be sensibly handled manually. This article provides definitions and structures for the assessment of the usefulness of 3D geovisualization so that hopefully future technological developments will be driven by theory and less out of "3D for 3D's sake" Shepherd (2008, p. 200). 


\subsection{Goals}

This article aims to review and compile different definitions and considerations as a basic framework for evaluating the usefulness and appropriateness of 3D geovisualizations. A special focus lies on 3D geovisualization for the purpose of exploratory data analysis. The definitions and structures offered take into account the specific characteristics of 3D geovisualizations and enable the considerations necessary for the evaluation of $3 \mathrm{D}$ geovisualization and thus ultimately $3 \mathrm{D}$ geovisualization theory building. Generally, it is aimed to look at non-technical aspects such as usefulness, purpose or design decisions.

Focussing on 3D geovisualizations for exploratory and analytical purposes is based on thought and information (e.g. Petzold \& Matthias 2011) that 3D geovisualizations are more useful when they not only depict the real world but include additional data, for example being "geospatial virtual "super environments' in which users can not only see what would be visible in the real world, but also experience the normally invisible" (MacEachren et al. 1999, p. 36). In relation, advice for the design of 2D exploratory data graphics is available. They should be displays of high data density and encourage comparison (Tufte 2001). Typically, visualizations are most often used at the end of the traditional geospatial data pipeline ranging from collection, modelling to visualization. Thus, visualizations often serve the purpose of communicating and presenting results, such as photo-textured 3D city models or flights through virtual environments. 3D geovisualizations are more rarely included in the data analysis process, for example as a tool for the exploration of data sets. But, there is great potential for exploratory $3 \mathrm{D}$ geovisualizations as much of the collected data are inherently spatial in three-dimensions, for example data from sensors in mountainous environments, in the oceans or midair. Such data may benefit from exploration and analysis in three dimensions. However, not only the technical feasibility but also the appropriateness or usefulness of such 3D geovisualizations needs consideration and evaluation.

The article first gives a definition of 3D geovisualization based on the geovisualization cube. Then the concepts of evaluating usability and usefulness are detailed before proposing a categorization of 3D geovisualizations as basis for data mapping and design considerations. Further, different task taxonomies are reviewed to help the purpose-based definition of tasks for the evaluation of usefulness. The article closes with a discussion of the presented structures and their value.

\section{CHARACTERISTICS OF 3D GEOVISUALIZATION}

\subsection{Technology and purpose}

3D visualization relies heavily on computer graphics, the technologies to create and manipulate digital images of 3D objects and scenes. Important aspects in regard to $3 \mathrm{D}$ geovisualization include, for example, the efficient handling of meshes, the basic structure of $3 \mathrm{D}$ objects, and very large amounts of data, texture mapping and the quality and efficiency of the rendering process creating the image viewed on the screen. Geovisualization is defined more methodically than technically. It integrates different approaches from fields such as cartography, exploratory data analysis and information visualization "to provide theory, methods, and tools for visual exploration, analysis, synthesis, and presentation of geospatial data" (MacEachren \& Kraak 2001). These different purposes of geovisualizations are illustrated through the geovisualization cube (Figure 1). The three continuums of characteristics, user or audience (public vs. expert), interaction (high vs. low) and information content (unknown vs. known), are mapped to the three axes of the cube and used to differentiate between different geovisualization purposes from exploration of a rather unknown data set to the communication of known information. For example, an exploratory geovisualization is typically highly interactive and allows the expert user to detect previously unknown information or patterns in a data set. For 3D geovisualizations we can base our definitions on the cube but we need to be more specific especially about the aspect of interaction which often includes aspects of navigation. For example, when using virtual globes also the lay user of that 3D geovisualization is faced with the task of navigation. Virtual globe applications often represent the real world and thus communicate information. While the geovisualization cube assumes high interaction mainly for exploratory purposes of expert users in some 3D geovisualizations (e.g. virtual globes) also the lay user needs to interact or navigate even without the aim of exploring an unknown data set.

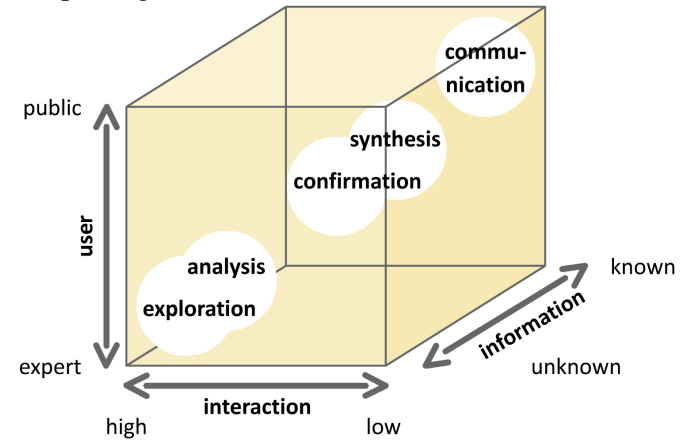

Figure 1. The purposes of geovisualization from exploration to communication illustrated in the geovisualization cube (adapted from MacEachren \& Kraak 2001)

\subsection{Interaction and navigation}

Most often 3D geovisualization is dynamic and allows for change of the display based on the input of the human operator. Interaction is a somewhat generic term comprising the process of a human communicating with the computer. Interaction and navigation are thus not exactly separable but for the following considerations interaction is defined to be the process of interaction with the data and display aiming at gaining insight. Examples of this type of interaction are especially useful for exploratory tasks and could include the re-expression of the data by mapping it to another display element or a different visual variable or filtering the data and displaying only a subset. Navigation is then defined as the interaction with the display to, for example, get an overview, look at different parts of the 3D geovisualization or look at it from different angles. However, these definitions are overlapping. Navigational aspects such as zooming in may have the same visual effect as selecting a subset of data.

Navigation and interaction in 2D and especially 3D displays is generally regarded as a (cognitive) cost (e.g. Wickens \& Baker 1995, Ware \& Plumlee 2005, Nielson 2007 or Shepherd 2008). However, especially navigation is an important part of 3D geovisualization as it allows the user to overcome occlusion (e.g. making hidden objects visible through a change of the viewpoint) or to look at the information from a different angle (a form of re-expression). 


\section{ASPECTS OF EVALUATING 3D GEOVISUALIZATIONS}

\subsection{Usability vs. usefulness}

The ISO standard 9241 defines usability as "the effectiveness, efficiency and satisfaction with which specified users achieve specified goals in particular environments" (in Dix et al. 1998, p. 277). This definition also includes to some degree the usefulness of a system or application, for example a 3D geovisualization. However, typically more often the usability or technical aspects of a visualization, e.g. how well is a specific application useable, is the user able to orientate himself or are the buttons in places where they are accessible, are evaluated. This is often useful but not always appropriate (Greenberg \& Buxton 2008). Considering aspects such as fulfilment of purpose or appropriateness of a 3D geovisualization are more difficult to measure and more rarely done (Lam et al. 2011, Plaisant 2004). Thus, the following considerations ignore somewhat the wholeness of the ISO definition and consider useable and useful separately. For example, consider having five different options to change the colours of your data display. These options are easily accessible and you successfully and quickly figured out how to change the colours. The conclusion is that these colour change options are well usable, have a high usability. However, only one colour scheme of the five may make sense for your data, the other four are much less useful or appropriate. In the case of colour the theory about what colour to choose for what type of data and in what type of (2D) situation largely exists (e.g. Harrower \& Brewer 2003). However, for many of the aspects involved in $3 \mathrm{D}$ geovisualization the theory and design guidelines do not yet exist and suitable evaluation is needed (Slocum et al. 2001, Ellis \& Dix 2006). While the following discussion talks more about usefulness or appropriateness, the more technical aspects of usability should not be forgotten. A useful system that is not usable is as useless as an inappropriate system that is highly usable (Landauer 1995).

\subsection{Design and supportive technology}

Based on the geovisualization cube we can consider the purpose of geovisualizations including 3D geovisualizations. Thinking about the type of users or the audience of 3D geovisualization, the interaction and navigation needed and also the type of information that is displayed is the first step in the process of deciding how to display the data in 3D. The results of such thinking may also result in creating a $2 \mathrm{D}$ visualization or a combination of $2 \mathrm{D}$ and $3 \mathrm{D}$ visualizations instead of a 3D visualization. Slocum et al. (2001) also note the need for suitably integrating visible-tangible data about landscapes and non-visible and abstract data, the mix of realism and abstraction. They go on stating that appropriate mixes of, for example, cartographic, graphic and statistical approaches to understand geodata and the variation of this mix in relation to applications need to be determined. Even though theory and design guidelines for 3D geovisualizations are yet missing, we can base our considerations on a number of established theories from related areas such as cartography, information visualization or human-computer interaction. Where the creation of a specific application for well-known users is the goal, a user-centred design approach may be beneficial to follow (Fuhrmann et al. 2005).

While we can improve the designs through considering existing theory we also need to question and improve current technology. For example, a large number of 3D scientific visualizations employ the rainbow colour scheme even though it is difficult to interpret (Borland et al. 2007) and better colour schemes exist (e.g. Light \& Bartlein 2004). However, current technology easily supports the rainbow colour scheme and we need the explicit decision for a different colour scheme and potentially also some effort to realise it. However, making conscious design decisions helps later evaluation and theory building. Based on the outcomes of an evaluation the initial design choices can be reconsidered and thus learned how the specific characteristics of 3D geovisualizations require different design decision.

\section{USING 3D SPACE}

A number of guidelines and advice exist for the decision of how data and information should be represented (e.g. Bertin 2010, Tufte 2001). That the consideration of these guidelines can be valuable also in $3 \mathrm{D}$ geovisualization settings is shown through the reasoning and evaluation of different data displays in virtual globes (Bleisch 2011). Additionally, in 3D we have to consider how the 3D space to display or map the data is used.

Elmqvist \& Tudoreanu (2007) distinguish between two reasons for creating 3D 'virtual worlds': 1) using 3D as a canvas for abstract information and 2) replicating the real world and its objects. Additionally, we can think about a combination of these two reasons, 3) combining replications of the real world or parts of the real world with additional abstract information. Both the categories 2) and 3) can be termed 3D geovisualization. While category 2) may typically serve the purpose of communication, e.g. showing the world digitally, category 3) may serve the whole range of purposes as defined through the geovisualization cube (Figure 1).

\subsection{Category 1) - 3D representations of abstract data}

In this category the 3D representations display mainly abstract data or information potentially combined with selected objects of the real world (e.g. parts of the human body for medical visualizations). Most often a local coordinate system is used. The three axes or $\mathrm{x}, \mathrm{y}$, and $\mathrm{z}$ coordinates of the display are used to show data values and, where needed, context information. Typical examples of 3D representations belonging to this category are scientific visualizations. Further examples include data only $3 \mathrm{D}$ displays that employ spatial metaphors for data communication (spatializations).

\subsection{Category 2) - 3D representations of the real world}

This category comprises 3D representations of the real world and/or its objects in realistic or abstract/generalised ways. The $\mathrm{x}, \mathrm{y}$, and $\mathrm{z}$ coordinates of these displays are mainly used to show the real world dimensions easting, northing and elevation and/or the dimensions, including height, of buildings or other objects. Digital city models and virtual globes such as Google Earth are typical examples of this category of 3D representations. 3D representations aiming to represent real environments typically consist of a digital elevation or surface model with some sort of drape. In case they are designed to look realistic the drape often consists of high resolution ortho imagery (Lange 1999) but satellite imagery or maps are also used. Depending on investment, 3D city models are modelled in more or less detail. Often additional detail is suggested through photo texturing of the facades while the details are not explicitly modelled in the underlying geometric model. Much research is concerned with automating the detailed construction and 
realistic visualization of city models (see e.g. Nebiker et al. 2010 for an overview). However, the cognitive aspects of textured city models are rarely taken account of.

\subsection{Category 3) - 3D representations of the real world and abstract data in combination}

The proposed third category enhances the more or less realistic representation of the real world environment with additional data displays. Here the three axes of the virtual environment, the $\mathrm{x}, \mathrm{y}$, and $\mathrm{z}$ coordinates, are used to show real world dimensions and at the same time also data values. It is this type of 3D geovisualization which may come closest to the proposed vision of Digital Earth (Craglia et al. 2012) as it can be used to integrate representations of a wide range of data with spatial reference into representations of the real world. An example for this category is the 3D visualization of the data collected by the Copenhagen Wheel (Ratti et al. 2010) within the virtual city of Copenhagen (Figure 2). Some rare advice on how to use the three dimensions of space is offered by Ware \& Plumlee (2005). They recommend using the $\mathrm{x}$ and $\mathrm{y}$ axes of the screen coordinates (orthogonal to the line of sight) to display information rather than the $\mathrm{z}$ axis, the depth of the 3D environment (along the line of sight). The latter is more difficult to interpret. Application of this recommendation may result in restricting navigation or using billboards, data graphics which always face the viewer (Bleisch 2011).

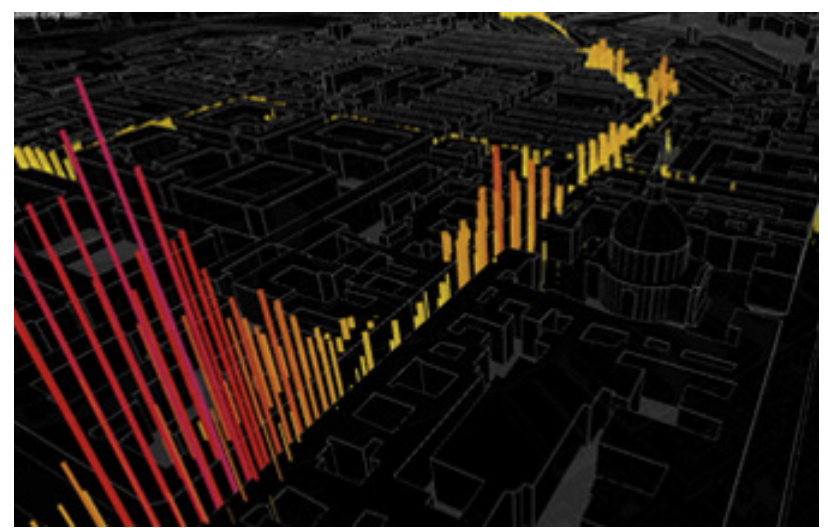

Figure 2. Environmental information displayed as bars in virtual 3D Copenhagen (Copenhagen Wheel project, Ratti et al. 2010), an example of combining 3D representations of the real world with abstract data; according to Ware \& Plumlee (2005) the data could be best interpreted when displayed orthogonally to the line of sight (data line rotated about $45^{\circ}$ in this display)

\subsection{Other terms and categories in use}

The borders between the categories defined here are neither clear cut, nor is there a convention for naming them. For example, Polys \& Bowman (2004) name their mainly scientific 3D visualizations enhanced with labels and some other additional information "information rich virtual environments" or Bodum (2005) offers a categorisation of virtual environments in geovisualization based on the degree of realism/immersion and temporal characteristics. A categorisation of "spatial iconicity" for virtual environments is presented by MacEachren et al. (1999, p. 36). Their three generic categories 'abstract', 'iconic', and 'semi-iconic' approximately match the categories presented above in this order. However, their definition of 'semi-iconic' virtual environments maps an abstract data value to one of the geographic dimensions (e.g. as done in space-time cubes visualizing timegeography, introduced by Hägerstrand
(1970), or with data surfaces) and does not take into account the potential of double or multiple use of one or several dimensions for depicting the real world and at the same time also abstract data values as in the third category defined above (section 4.3). Independent of their naming, defining different categories helps thinking about the options for mapping data onto 3D space, a design decision. Certainly there are a number of additional considerations that may need to be taken into account or evaluated, for example, the interpretability of mapping different data of potentially different scales to the same axes of $3 \mathrm{D}$ space.

\section{TASK DEFINITIONS}

An aspect that is closely related to interaction with data and navigating the display are the tasks that need to be fulfilled with a specific 3D geovisualization. Strongly based on the purpose of the visualization the tasks are key when evaluating usefulness. The tasks are certainly simpler or less important if the purpose of the $3 \mathrm{D}$ geovisualization is communication and more complex and in focus if the purpose is data exploration. The definition of tasks is a complex issue in geovisualization evaluations (Tobon 2005). Searching the literature yields numerous task definitions and also numerous studies which apply them. Interaction taxonomies (e.g. Yi et al. 2007) often combine navigation, data display manipulation and tasks. As detailed above, for 3D geovisualizations which are interactive by nature it is helpful to be able to separate between the different types of tasks. The following review of task definitions focusses on the use of 3D geovisualization for exploratory purposes, for example, analysing a set of data in relation to the surrounding landscape. Additionally, they are reviewed in regard to their suitability for attempting the evaluation of usefulness of a $3 \mathrm{D}$ geovisualization in relation to its purpose rather than for measuring usability. Thus, suitable task definitions are required which can appropriately reflect the goals aimed for. The difficulty with most task definitions is that they are quite tool based, for example, overview, filter or details-on-demand (Shneiderman 1996), computational as, for instance, retrieve value, find extremums or sort (Amar et al. 2005), or pre-defined data analysis tasks. Examples for often used data analysis tasks include identify, compare or categorise as defined in task taxonomies by Wehrend \& Lewis (1990), Keller \& Keller (1993) or Zhou \& Feiner (1998). Such task definitions are also used for the evaluating of geovisualizations (e.g. Koua et al. 2006, Nekrasovski et al. 2006, Morse et al. 2000). Additionally, adaptations and/or extensions of these task taxonomies are proposed and implemented by a number of researchers (e.g. Valiati et al. 2006, Xiang et al. 2005 or Ogao \& Kraak 2002). For the analysis of data in 3D geovisualizations, however, we are looking for tasks that are able to integrate the third dimension or even allow for specific definitions of data analysis tasks in relation to 3D space, for example the analysis of a relationship of data with the surrounding $3 \mathrm{D}$ environment.

The functional view of data and tasks defined by Andrienko \& Andrienko (2006) is based on the distinction between characteristic and referential component of data. The characteristics of data are, for example, the measurement values or observations and the referential component specifies the context, such as a place, an altitude or 3D space in general. Thus, a data set can be viewed as a set of links between references and characteristics. Based on this data definition data analysis tasks can be defined in terms of the two data components characteristics and references. Andrienko \& Andrienko (2006) differentiate between elementary tasks dealing with single elements of data (e.g. single characteristic or 
reference) or synoptic tasks dealing with a set of references or characteristics. The task is then defined as having a target (what needs to be known) and having constraints (what is already known and has to be taken into account). For example, an elementary task (direct lookup) is defined as wanting to know the characteristics of the data (target) at a specific reference (constraint) or, more applied, finding out the measured value at a given location. Based on this logic of characteristics and references Andrienko \& Andrienko (2006) define lookup, comparison and relation-seeking tasks on the elementary and synoptic level. In comparison to the task definitions reviewed above, this task definition is better suited to exactly define the tasks relevant for a specific purpose and separate them from general navigational tasks. It may thus help the focussed evaluation of 3D geovisualization usefulness. For comparisons of results between different visualization evaluation studies, it is helpful that most of the data analysis tasks defined by other researchers (e.g. Wehrend \& Lewis 1990, Keller \& Keller 1993, Zhou \& Feiner 1998), can also be defined using Andrienko \& Andrienko's (2006) functional data and task definition.

\section{DISCUSSION}

A technology-driven approach to $3 \mathrm{D}$ geovisualization is to some degree based on the (implicit) assumption " $3 \mathrm{D}$ geovisualizations are useful". However, this assumption should be proved to be either true or false in relation to specific applications. Depending on purpose and data we may come to either conclusion. This paper discusses 3D geovisualizations by characterising important aspects and offers a categorisation of the use of $3 \mathrm{D}$ space, an important design decision, as well as making a review of different task definitions. It does so in the aim to provide some basic structure for the consideration and evaluation of 3D geovisualization usefulness or appropriateness in different contexts.

We are yet missing detailed 3D geovisualization theory. But 3D geovisualizations should nevertheless be created based on reasoned design and decisions about intention and purpose. Typical questions may include, what data to map onto what dimension of space, onto what visual variable, what is the goal or what purpose and users shall the 3D geovisualization satisfy or what are the tasks to be fulfilled. The reasoning can be based on existing theories and guidelines from related disciplines such as cartography, information visualization or human-computer interaction but should take into account the specific characteristics of 3D such as perspective displays or the need for navigation which may be different from interaction tasks. Thus, considering the differences between 2D theory and 3D application, making informed design decisions and reviewing those decisions through evaluations will bring us towards 3D geovisualization guidelines.

While this article offers some structure for considering the usefulness of 3D geovisualizations, it does not discuss evaluation in general (see e.g. Plaisant 2004) or evaluation metrics. Usability is typically evaluated based on efficiency and effectiveness (e.g. Mackinlay 1986 or van Wijk 2005), for example, through measuring task completion time and success or error rates (e.g. Chen \& Yu 2000 or Tory et al. 2006). However, such measures generally need clear answers for the tasks. It is more difficult to evaluate somewhat ill-defined tasks which are often present in exploratory settings. North (2006) proposes an evaluation approach based on measuring insight to address this difficulty. Applications of this approach can be found in Saraiya et al. (2005) and Rester et al. (2007).
3D geovisualization is more than technology, such as 3D computer graphics or 3D rendering, even though technological developments are important. However, in the light of future 3D geovisualization theory building we should aim to make conscious design and purpose decisions and also evaluate the created 3D geovisualizations in regard to their usefulness or appropriateness. The results of those evaluations can then improve future 3D geovisualization designs and initiate technological developments out of specific needs. The presented definitions and considerations will hopefully take the discussion about the usefulness as well as the implementation of 3D geovisualizations for different purposes further and may allow 3D geovisualizations to become an important tool for the visual exploration of 3D geospatial data sets.

\section{REFERENCES}

Amar, R., Eagan, J. \& Stasko, J., 2005. Low-Level Components of Analytic Activity in Information Visualization. IEEE Symposium on Information Visualization (INFOVIS'05). Minneapolis, pp. 111-117.

Andrienko, N. \& Andrienko, G., 2006. Exploratory Analysis of Spatial and Temporal Data: A Systematic Approach, Springer, Berlin.

Bartoschek, T. \& Schönig, J., 2008. Trends und Potenziale von virtuellen Globen in Schule. GIS Science, (4), pp. 28-31.

Bertin, J., 2010. Semiology of Graphics: Diagrams, Networks, Maps, ESRI Press.

Bleisch, S., 2011. Toward Appropriate Representations of Quantitative Data in Virtual Environments. Cartographica: The International Journal for Geographic Information and Geovisualization, 46(4), pp. 252-261.

Bodum, L., 2005. Modelling Virtual Environment for Geovisualization: A Focus on Representation. In Exploring Geovisualization. Elsevier, Amsterdam, pp. 389-402.

Borland, D., Russell, M. \& Carolina, N., 2007. Rainbow Color Map (Still) Considered Harmful. IEEE Computer Graphics and Applications, (March/April), pp. 14-17.

Chen, C. \& Yu, Y., 2000. Empirical studies of information visualization: a meta-analysis. Int. J. Human-Computer Studies, 53, pp. 851-866.

Craglia, M. et al., 2012. Digital Earth 2020 : towards the vision for the next decade. Int. J. of Digital Earth, 5(1), pp. 4-21.

Dix, A.J. et al., 1998. Human-Computer Interaction. $2^{\text {nd }}$ ed., London: Prentice Hall.

Döllner, J. \& Walther, M., 2003. Real-Time Expressive Rendering of City Models. In Proc of $7^{\text {th }}$ International Conference on Information Visualization (IV'03). London.

Ellis, G. \& Dix, A., 2006. An Explorative Analysis of User Evaluation Studies in Information Visualisation. In BELIV 2006, Venice, Italy.

Elmqvist, N. \& Tudoreanu, M.E., 2007. Occlusion Management in Immersive and Desktop 3D Virtual Environments: Theory and Evaluation. The Int. J. of Virtual Reality, 6(2), pp. 21-32.

Fuhrmann, S., Ahonen-Rainio, P., et al., 2005. Making Useful and Useable Geovisualization: Design and Evaluation Issues. In Exploring Geovisualization. Elsevier, Amsterdam, pp. 553-566. Goodchild, M.F., 1999. Implementing Digital Earth: A Research Agenda. In Towards Digital Earth - Proc of the Int. Symposium on Digital Earth. Science Press, pp. 21-26.

Google, 2011. Google Earth. http://earth.google.com/intl/de/ (5 Nov 2011).

Gore, A., 1998. The Digital Earth: Understanding our planet in the 21 st Century, OGC. 
Greenberg, S. \& Buxton, B., 2008. Usability evaluation considered harmful (some of the time). In Proc of the $26^{\text {th }}$ annual CHI conference on Human factors in computing systems - CHI '08. Florence, pp. 111-120.

Hägerstrand, T., 1970. What about people in regional science? In Papers of the Regional Science Assoc., Vol. XXIV. pp. 7-21. Harrower, M. \& Brewer, C.A., 2003. ColorBrewer.org: An Online Tool for Selecting Colour Schemes for Maps. The Cartographic Journal, 40(1), pp. 27-37.

Keller, P.R. \& Keller, M.M., 1993. Visual Cues: Practical Data Visualization, IEEE Computer Society Press, Los Alamitos.

Koua, E.L., MacEachren, Alan M \& Kraak, Menno-Jan, 2006. Evaluating the usability of visualization methods in an exploratory geovisualization environment. Int. J. of Geographical Information Science, 20(4), pp. 425-448.

Lam, H., Bertini, E., et al., 2011. Empirical Studies in Information Visualization: Seven Scenarios. IEEE Transactions on Visualization and Computer Graphics.

Landauer, T., 1995. Usefulness and Usability. In The Trouble with Computers: usefulness, usability, and productivity. MIT Press, Cambridge, pp. 141-167.

Lange, E., 1999. The Degree of Realism of GIS-Based Virtual Landscapes: Implications for Spatial Planning. In Photogrammetric Week 99. Wichmann, pp. 367-374.

Leonowicz, A.M., Jenny, B. \& Hurni, L., 2010. Automated Reduction of Visual Complexity in Small-Scale Relief Shading. Cartographica: The Int. J. for Geographic Information and Geovisualization, 45(1), pp. 64-74.

Light, A. \& Bartlein, P.J., 2004. The End of the Rainbow? Color Schemes for Improved Data Graphics. Eos, 85(40), pp. 385-391.

MacEachren, Alan M \& Kraak, Menno-Jan, 2001. Research Challenges in Geovisualization. Cartography and Geographic Information Science, 28(1).

MacEachren, Alan, et al., 1999. Virtual environments for geographic visualization: Potential and challenges. In Proc of ACM Workshop on New Paradigms in Information Visualization and Manipulation. Kansas City, pp. 35-40.

Mackinlay, J., 1986. Automating the design of graphical presentations of relational information. ACM Transactions on Graphics, 5(2), pp. 110-141.

Morse, E., Lewis, M. \& Olsen, K.A., 2000. Evaluating visualizations: using a taxonomic guide. Int. J. HumanComputer Studies, 53(5), pp. 637-662.

Mower, J.E., 2011. Supporting Automated Pen and Ink Style Surface Illustration with B-Spline Models. Cartography and Geographic Information Science, 38(2), pp. 174-183.

Nebiker, S., Bleisch, S. \& Christen, M., 2010. Rich point clouds in virtual globes - A new paradigm in city modeling? CEUS, 34(6), pp. 508-517.

Nekrasovski, D. et al., 2006. An Evaluation of Pan\&Zoom and Rubber Sheet Navigation with and without an Overview. In CHI 2006 Proceedings. Montreal, Quebec, Canada.

Nielsen, A., 2007. A Qualification of 3D Geovisualisation. PhD. Aalborg University.

North, C., 2006. Toward Measuring Visualization Insight. IEEE Computer Graphics and Applications, 26(3), pp. 6-9.

Ogao, P.J. \& Kraak, Menno-Jan, 2002. Defining visualization operations for temporal cartographic animation design. International Journal of Applied Earth Observation and Geoinformation, 4, pp. 23-31.

Petzold, B. \& Matthias, E., 2011. Killerapplikation gesucht. gis.BUSINESS, 7, pp. 40-42.

Plaisant, C., 2004. The Challenge of Information Visualization Evaluation. In IEEE Proc. of AVI 2004, pp. 109-116.
Polys, N.F. \& Bowman, D.A., 2004. Design and display of enhancing information in desktop information-rich virtual environments: challenges and techniques. Virtual Reality, 8(1), pp. 41-54.

Ratti, C. et al., 2010. copenhagen wheel project. http://senseable.mit.edu/copenhagenwheel/urbanData.html (5 Nov 2011).

Rester, M. et al., 2007. Evaluating an InfoVis Technique Using Insight Reports. In E. Banissi et al., eds. 11th Int. Conference Information Visualization, IV2007. Zürich, pp. 693-700.

Saraiya, P., North, C. \& Duca, K., 2005. An Insight-Based Methodology for Evaluating Bioinformatics Visualizations. IEEE Transactions on Visualization and Computer Graphics, 11(4), pp. 443 - 456.

Shepherd, I.D.H., 2008. Travails in the Third Dimension: A Critical Evaluation of Three-dimensional Geographical Visualization. In Geographic Visualization: Concepts, Tools and Applications. Wiley, Chichester, pp. 199-222.

Shneiderman, B., 1996. The Eyes Have It: A Task by Data Type Taxonomy for Information Visualizations. Proc. Visual Languages 96.

Slocum, T.A. et al., 2001. Cognitive and Usability Issues in Geovisualization. Cartography and Geographic Information Science, 28(1), pp. 61-75.

Tobon, C., 2005. Evaluating Geographic Visualization Tools and Methods: An Approach and Experiment Based upon User Tasks. In Exploring Geovisualization. Elsevier, Amsterdam, pp. 645-666.

Tory, M. et al., 2006. Visualization Task Performance with 2D, $3 \mathrm{D}$ and Combination Displays. IEEE Transactions on Visualization and Computer Graphics, 12(1), pp. 2-13.

Tufte, E.R., 2001. The Visual Display of Quantitative Information $2^{\text {nd }}$ ed. Graphics Press, Cheshire.

Valiati, E.R.A., Pimenta, M.S. \& Freitas, C.M.D., 2006. A taxonomy of tasks for guiding the evaluation of multidimensional visualizations. In 2006 AVI workshop on Beyond time and errors: novel evaluation methods for information visualization. Venice, pp. 1-6.

Ware, C. \& Plumlee, M., 2005. 3D Geovisualization and the Structure of Visual Space. In Exploring Geovisualization. Elsevier, Amsterdam, pp. 567-576.

Wehrend, S. \& Lewis, C., 1990. A Problem-oriented Classification of Visualization Techniques. In IEEE Visualization 90. San Francisco, pp. 139-143.

Wickens, C.D. \& Baker, P., 1995. Cognitive Issues in Virtual Reality. In W. Barfield \& T. A. Furness, eds. Virtual Environments and Advanced Interface Design. Oxford University Press, New York, pp. 514-541.

van Wijk, J.J., 2005. The value of visualization. In Proceedings of IEEE Visualization 2005. IEEE, pp. 79-86.

Wood, J. et al., 2005. Using 3D in Visualization. In Exploring Geovisualization. Elsevier, Amsterdam, pp. 295-312.

Xiang, Y. et al., 2005. Visualizing criminal relationships: comparison of a hyperbolic tree and a hierarchical list. Decision Support Systems, 41, pp. 69-83.

Yi, J.S. et al., 2007. Toward a Deeper Understanding of the Role of Interaction in Information Visualization. IEEE Trans. on Visualization \& Computer Graphics, 13(6), pp. 1224-1231. Zhou, M.X. \& Feiner, S.K., 1998. Visual Task Characterization for Automated Visual Discourse Synthesis. In Computer Human Interaction CHI98. Los Angeles, pp. 392-399. 